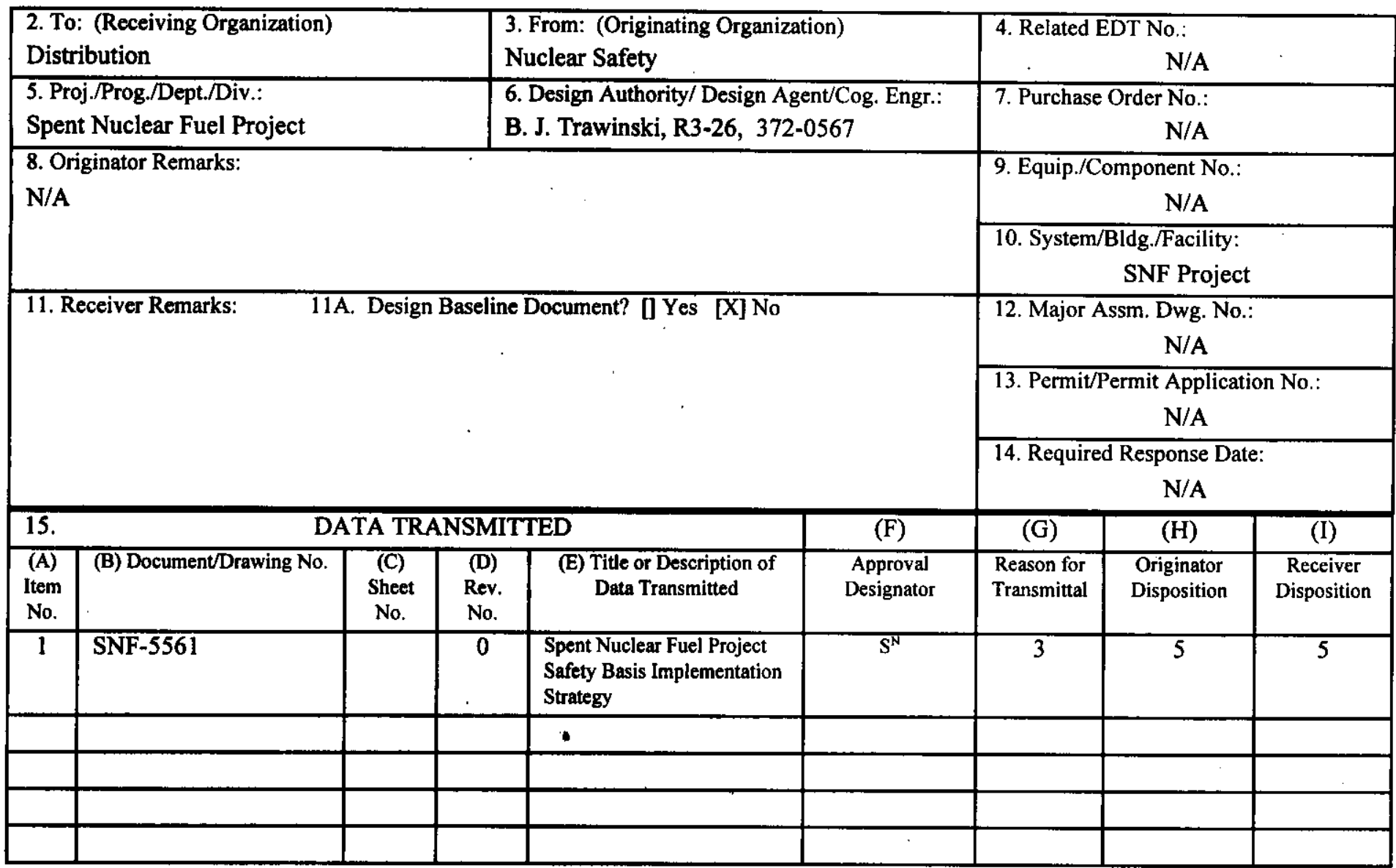

16.

\begin{tabular}{|l|}
\hline \multicolumn{1}{|c|}{ Approval Designator (F) } \\
\hline E, S, Q, D or N/A \\
(see WHC-CM-3-5, \\
Sec.12.7) \\
\hline
\end{tabular}

\begin{tabular}{l}
\hline \\
1. Approval \\
2. Release \\
3. Information \\
\hline
\end{tabular}

Reason for Transmittal (G)

4. Review

5. Post-Review

6. Dist. (Receipt Acknow. Required)

KEY

(See Approval Designator for required signatures)

\begin{tabular}{|c|c|l|c|c|c|}
\hline $\begin{array}{c}\text { (G) } \\
\text { Reason }\end{array}$ & $\begin{array}{c}\text { (H) } \\
\text { Disp. }\end{array}$ & (J) Name (K) Signature (L) Date (M) MSIN & $\begin{array}{c}\text { (G) } \\
\text { Reason }\end{array}$ & $\begin{array}{c}\text { (H) } \\
\text { Disp. }\end{array}$ & (J) Name (K) Signature (L) Date (M) MSIN \\
\hline & & Design Authority N/A & & & \\
\hline & & Design Authority N/A & & & \\
\hline 1 & 1 & Cog.Eng. B. J. Trawinski & & \\
\hline 1 & 1 & Cog. Mgr. J. D. Carison & & \\
\hline 1 & 1 & Operations J. E. Truax & & \\
\hline 1 & 1 & Nuclear Safety J. D. Zurlson & & \\
\hline 1 & 1 & Engineering W. C. Miller & & \\
\hline
\end{tabular}

18.
B. Trawinski
Signature of EDT
Originator

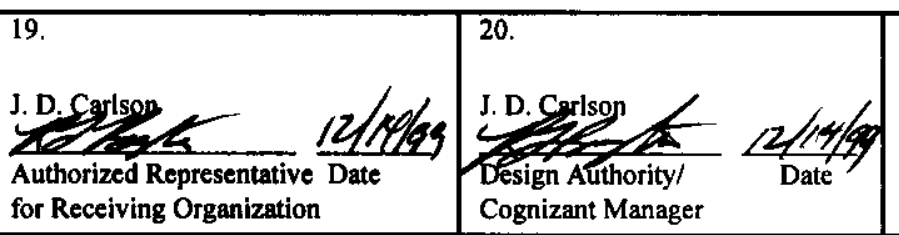

Disposition (H) \& (I)

4. Reviewed no/comment

5. Reviewed w/comment

6. Receipt acknowledged
21. DOE APPROVAL (if required)

Ctrl. No.

[] Approved

[] Approved w/comments

[] Disapproved w/comments 


\section{Spent Nuclear Fuel Project Safety Basis Implementation Strategy}

Brian J. Trawinski

WSMS/Fluor Daniel Hanford, Inc. Richland, WA 99352

U.S. Department of Energy Contract DE-AC06-96RL13200

EDT $\quad 628127$

Org Code: $2 \mathrm{~F} 200$

B\&R Code: 39EW40400
UC: 620

Charge Code: $105625 /$ CB80

Total Pages:

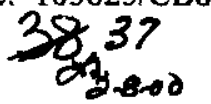

Key Words: Spent Nuclear Fuel, Safety Basis, Implementation

The objective of the Safety Basis Implementation is to ensure that implementation of activities is accomplished in order to support readiness to move spent fuel from $\mathrm{K}$ West Basin. Activities may be performed directly by the Safety Basis Implementation Team or they may be performed by other organizations and tracked by the Team. This strategy will focus on five key elements, (1) Administration of Safety Basis Implementation (general items), (2) Implementing documents, (3) Implementing equipment (including verification of operability, (4) Training, (5) SNF Project Technical Requirements (STRS) database system.

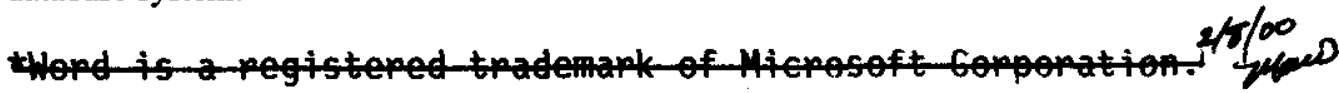

TRADEMARK DISCLAIMER. Reference herein to any specific commercial product, process, or service by trade name, trademark, manufacturer, or otherwise, does not necessarily constitute or imply its endorsement, recommendation, or favoring by the United States Government or any agency thereof or its contractors or subcontractors.

Printed in the United States of America. To obtain copies of this document, contact: Document Control Services, P.O. Box 950, Mailstop H6-08, Richland WA 99352, Phone (509) 372-2420; Fax (509) 376-4989.

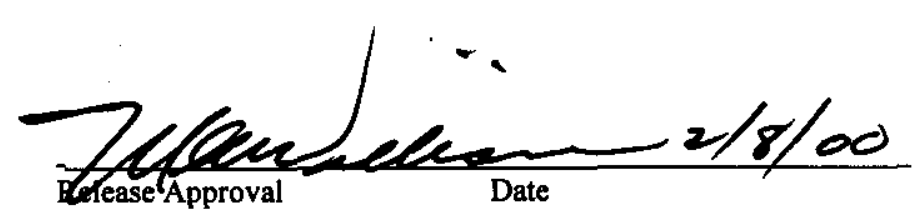

Approved for Public Release

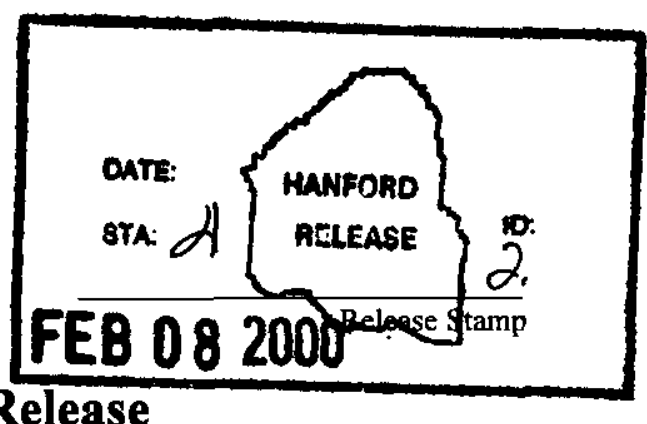


SNF-5561 REV 0

\section{SPENT NUCLEAR FUEL PROJECT SAFETY BASIS IMPLEMENTATION STRATEGY}




\section{APPROVALS}

Prepared/Approved: $\frac{\text { Safety Basis Implementation }}{\text { for Brian Trawinsk: }}$

Approved:

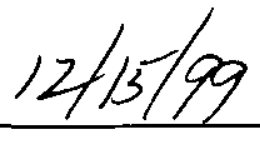

Spent Nuclear Fuel Nuclear Safety

Approved: $\quad$ WC W/We 2/2/00

Spent Nuclear Fuel Engineering

Approved:

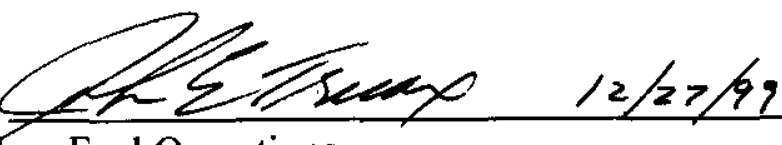

Spent Nuclear Fuel Operations 


\section{REVISION HISTORY}

Revision 0 is the initial issue of this document, and provides the baseline description of the Safety Basis implementation strategy and required resources. Revision 0 will be used as supporting information for a Deviation Notice/Baseline Change Request (DN/BCR) to obtain funding for unfunded resources. Subsequent revisions to this document will be evaluated to determine if additional funding is required. 


\subsection{PURPOSE}

The purpose of this Implementation Strategy document is to propose a comprehensive strategy for Safety Basis implementation at each Spent Nuclear Fuel (SNF) Project facility that focuses on the following five key elements:

- Administration of Safety Basis Implementation (General Items)

- Implementing Documents

- Implementing Equipment (including verification of operability)

- Training

- SNF Project Technical Requirements (STRS) database system

Safety Basis Implementation will be coordinated and carried out by a Safety Basis Implementation Team which will report directly to the Deputy Operations Manager. The mission of the Safety Basis Implementation Team will be to ensure that all work related to Safety Basis implementation is accomplished in order to support readiness to move spent fuel from $\mathrm{KW}$ Basin. Activities may be performed directly by the Safety Basis Implementation Team, or they may be performed by other organizations and tracked by the Team. It should be noted, however, that this mission does not exclude activities necessary to bring K East (KE) Basin into compliance with revised Safety Basis requirements, as KE Basin will have to operate to the same set of $\mathrm{AB}$ documents as $\mathrm{KW}$ does. It should be noted, however, that requirements applicable to $\mathrm{KW}$ Basin may not be applicable to KE Basin, even though the AB documents may be the same.

This Implementation Strategy document was developed using best practices determined from existing SNF Project procedures and from the implementation approaches used at other facilities on the Hanford Site and across the U.S. Department of Energy (DOE) Complex.

Because this Implementation Strategy document is forward-looking, there is some uncertainty present in the details of scope, schedule, and resources. To compensate for this uncertainty, changes may be made to the Safety Basis Implementation approach without necessarily having to revise this Implementation Strategy document.

\subsection{BACKGROUND}

Uranium spent nuclear fuel (SNF) is currently stored in the $105 \mathrm{KE}$ Basin and the $105 \mathrm{KW}$ Basin, at the U.S. Department of Energy (DOE) Hanford Site in southeastern Washington. The SNF Project is responsible for operation of these fuel storage facilities. The SNF Project mission includes safe removal, repackaging, and transportation of SNF from these storage basins to a new storage facility in the 200 East Area. This mission includes modifying the existing KE and KW Basin facilities and constructing two new facilities: the $100 \mathrm{~K}$ Area Cold Vacuum Drying (CVD) Facility and the 200 East Area Canister Storage Building (CSB). A significant challenge to achieving readiness to start SNF operations is the successful implementation of the.Safety Analysis Reports (SARs) and associated Technical Safety Requirements (TSRs). SAR and TSR commitments will be reflected within many of the SNF Project Infrastructure programs. 
Training, procedures, operations, nuclear safety, maintenance, and worker safety, as well as generic programs, (i.e., radiation protection, waste management, fire protection, quality assurance [QA], etc.) will each contain actions to which the SAR or TSR commits.

\subsection{DEFINITIONS}

Administrative Procedure (AP), Controlled, mandatory administrative instructions and requirements of specific SNF Project processes which serve to implement the DOE orders, other company level requirements, and state and federal regulations.

Commitment. A statement in a Safety Basis document that protects the safety basis for the facility. Commitments have been defined as any concept in the SAR and its references that, (a) establishes guidelines for operations, reliability, availability, and maintainability of any system or subsystem that is required for operation of a facility within the risk accepted by DOE, (b) limits the risk accepted by DOE; or, (c) establishes a parametric value that if changed in any arbitrary manner could increase the risk relative to the safety or protection of the worker, the public or the environment. The definition of commitment includes key assumptions that must be protected. There are three general types of commitments in the Safety Basis: design commitments, operational commitments and commitments for institutional safety programs.

- Design commitments include the assumed physical configuration of the important-to-safety (e.g., Safety Class, Safety Significant, and potentially Defense-in-Depth systems, structures, and components; the facility-specific general design criteria; and stated requirements for modifications for important-to-safety systems, structures, and components. While some design commitments may not be specifically identified in the Safety Basis, design commitments are preserved through the facility configuration control and the facility modification processes. Design commitments are identified as requirements in the facility modification process or the modification supports a change in the design commitment.

- Operational commitments are requirements on important-to-safety systems, structures, and components operability; system and parameter surveillance activities; and specified parametric values that are under the control of the operating staff. Examples of operational commitments are the basin water level limits and the temperature monitoring limits. Inspection issues related to operational commitments will be evaluated. The above definition will be used to establish if the issue identifies an operational commitment. Once identified, commitments will be verified and implemented in procedures.

- Commitments to institutional safety programs include comprehensive descriptions of institutional programs. Examples are hazardous material protection, radiation protection, QA, conduct of operations, emergency preparedness and fire protection. Programmatic commitments encompass a large number of details that are more appropriately covered in specific program documents external to the Safety Basis. Safety Basis material related to the institutional safety programs will be evaluated to determine if it contains commitments or is descriptive only. 
Effective Date. Date when Safety Basis Implementation is declared, and the Implementing documents are available for use. For this process the $\mathrm{AB}$ documents and the implementing documents will be dated with the SAME effective date.

Implementation Plan. A document that describes the detailed actions, steps, and programs necessary to bring a facility, department, contractor, etc., into compliance with a set of mandated requirements.

Implementation Strategy. A document that describes in high-level terms the actions that must be taken to achieve the goal of effective Safety Basis Implementation. The Implementation Strategy document serves as a roadmap when developing the specific Implementation Plans for each facility.

Implementing Document. An operating, surveillance, or maintenance performance-oriented technical procedure, a SNF Project or Hanford administrative procedure, and/or a drawing or other controlled document which provides objective evidence of compliance with a TSR requirement or other SAR commitments. If the implementing document is performance based, then minimum expectations are as defined in the review criteria defined later in this document.

Plant Review Committee (PRC). The PRC is responsible for reviewing and approving actions required by process standards or procedures, which implement the TSRs and require procedure or physical plant modifications.

Potential Inadequacies. The intent of DOE 5480.21 is to provide for prompt and timely notification, but not to preclude a reasonable time period for confirmation. To take actions and notify DOE based upon unconfirmed information is not desirable. Therefore, the contractor should interpret "potential inadequacy" as allowing reasonable time to confirm the existence of an inadequacy, but not the time that may be necessary to evaluate all the implications of the inadequacy or to develop either revised analysis or other long-term corrective actions.

Process Change Authorizations (PCA) Limited or short-term changes to a Process Standard, often tailored to a specific work request.

Process Standards (PS). Working level documents which contains normal limitations governing the activities of Operations to guard against nuclear hazards, conserve the life of the facilities, ensure the safety of the employees and the surrounding area, comply with environmental standards, and ensure compliance with TSRs. Process Standards are considered to be a Source Document, although in some cases implementation (e.g., documentation of compliance) will be in a work package and not a procedure).

Source Document. A document that is part of the Safety Basis, and contains requirements to which the facility must adhere. This includes the SAR, TSR, and other AB documents (Safety Evaluation Reports [SERs], Justification for Conditional Operations [JCOs], etc.), and may also include Process Standards, Process Change Authorizations, and AB document references. 
Requirements Implementation Table/Matrix. A table/matrix that lists all active Safety Basis requirements, corresponding PS information, and appropriate implementation details (e.g., Implementing Document, section, type, unit operation, and optional discussion) for each requirement.

Safety Analysis Report (SAR) A report which documents the adequacy of safety analysis for a nuclear facility to ensure that the facility can be constructed, operated, maintained, shut down, and decommissioned safely and in compliance with applicable laws and regulations in accordance with DOE 5480.23 and guidance document, DOE-STD-3009-94.

Safety Basis Commitment Matrix (SBCM). The SBCM is a computer database; which provides a controlled reference source for all safety basis (SB) commitments. The database supports the operational phase of the facility by providing the following:

- a tool to assist in the Unreviewed Safety Question (USQ) process;

- a management tool to define and control all commitments made in the SB to a regulatory agency;

- a tool to determine the impact of the procedure revision process on SB commitments prior to making changes; and

- a management tool to demonstrate to third party review groups that the facility has adequate measures in place to identify and control the safety envelope.

STRS 2.0 (described later in this document) will serve as the SBCM for the SNF Project.

Self-Assessment Reports (compliance verification). Documented periodic review of the previous period's required TSR performance compliance against actual performance to correct any anomalies that could lead to a violation of the TSRs and to determine the overall effectiveness of performance assurance process. This process is currently required by NS-4-005.

Standard/Requirements Identification Document (S/RID). The S/RIDs are a total list of the Environmental, Safety and Health (ES\&H), Safeguards and Security (SAS), and Quality Assurance Requirements Description (QARD) standards/requirements applicable to a specific site, facility, or activity that, if fully implemented, would be expected to provide an adequate degree of protection to the public, the worker, and the environment.

Technical Safety Requirements (TSRs). Requirements that define the conditions, safe boundaries, and their bases, and the management controls required to ensure the safe operation of the facility.

Topical Area. A topical area like same subject procedures; e.g., administrative, environmental, operational.

TSR Requirement Verification. Compliance procedure performed by Facility Operations to verify the TSR and PS requirements are completed in a timely manner. 


\subsection{RESOURCES (SAFETY BASIS IMPLEMENTATION TEAM)}

The Safety Basis Implementation Team will be led by the Manager of Safety Basis implementation who will report directly to the SNF Deputy Operations Manager and be matrixed to the SNF Project Nuclear Safety Manager. Facility leads will functionally report to the Operations Facility Manager, and will take programmatic direction from the Safety Basis Implementation Manager. The team will be cross-functional, and will have members from Operations, Facility Engineering, Nuclear Safety, Training, and Procedures. Additional members may be required from Maintenance, Work Control, Startup Testing, Emergency Preparedness, and QA. The DOE will be invited to provide liaisons to the team; these liaisons will not be organizationally part of the team, but they will facilitate communication and foster faster resolution of issues. The organization is as depicted in Figure 1 below. Specific staffing needs will be determined as part of a staffing analysis being conducted as part of BCR development.

\section{Figure 1. SAFETY BASIS IMPLEMENTATION TEAM}

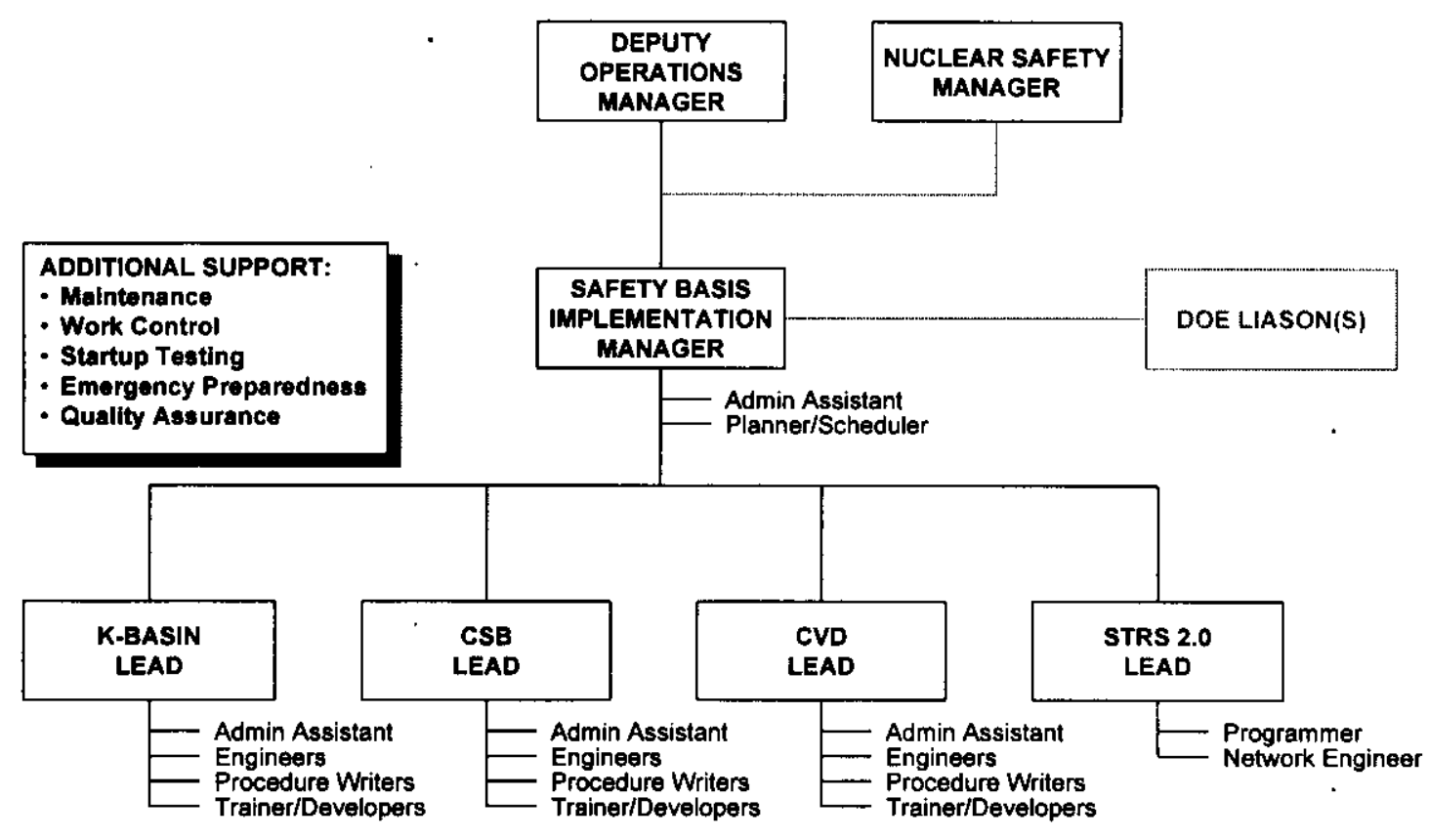

\subsection{SCOPE}

The scope of the Safety Basis implementation effort is as depicted in Figure 2 below. The scope includes all Safety Basis documents (e.g., the AB documents, plus references used to develop the $\mathrm{AB}$, and documents such as Process Standards / Process Change Authorizations that serve to further define or protect the $\mathrm{AB}$ requirements). The scope excludes the following: 
- Design basis documents, and design basis information contained in Safety Basis documents that is not related to maintaining the safety basis (e.g., general facility description of nonsafety-related systems);

- Detailed evaluation of compliance with design codes and standards referenced in the safety basis documents. Programmatic compliance (e.g., an administrative procedure/program that requires compliance with ASME B31.3 for all designs) is not excluded; and,

- Non-AB components of the Authorization Envelope (e.g., S/RIDs and Environmental Permits), unless included as part of the Safety Basis.

\section{Figure 2. SAFETY BASIS IMPLEMENTATION SCOPE}

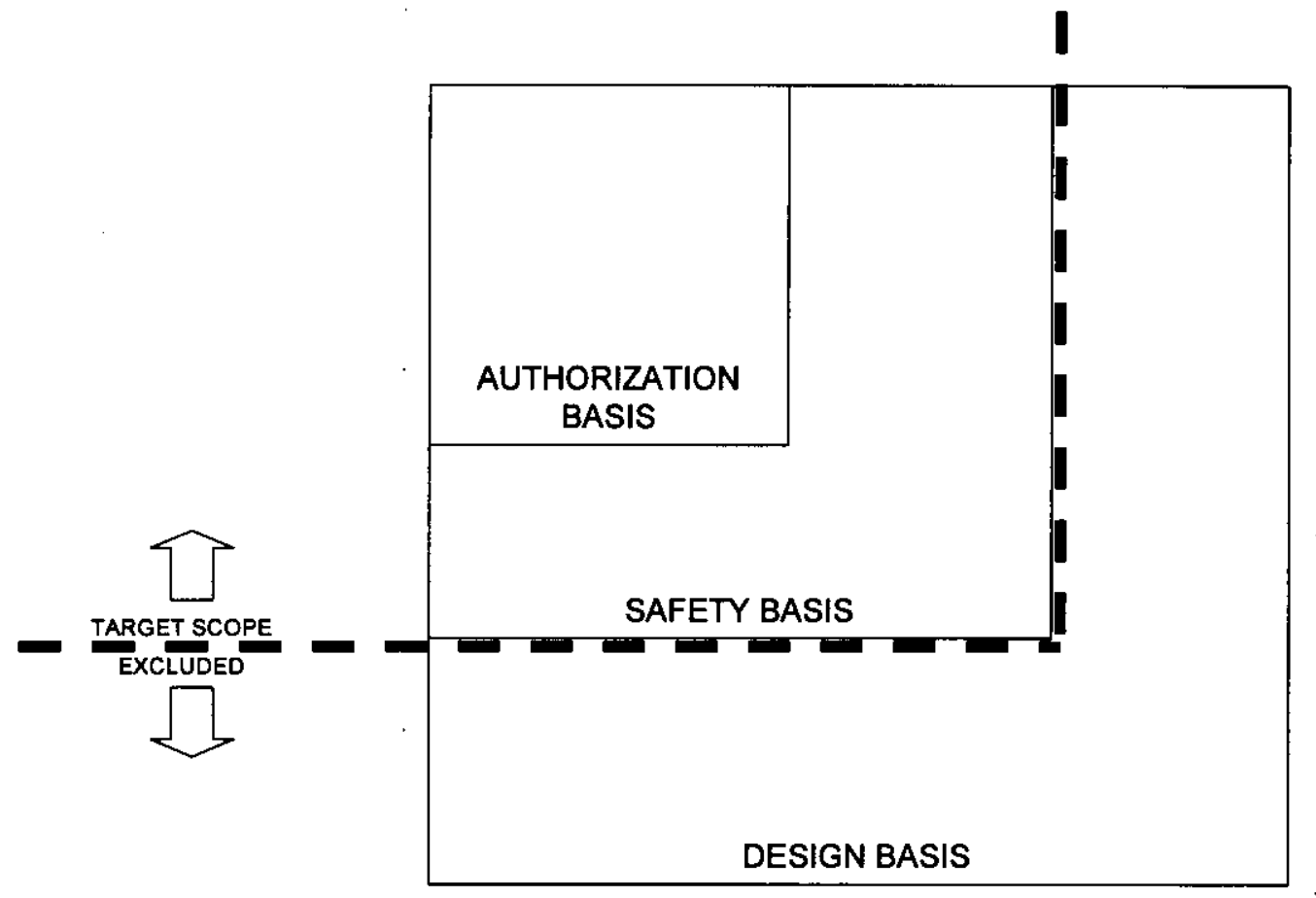

\subsection{SCHEDULE}

Figure 3 shows the target schedule for Safety Basis implementation. It assumes that full resources are available starting January 3,2000 . Since resources are currently extremely limited, activities that could start now (because Safety Basis documents are available) are being delayed. Based on when resources are made available, activities will either be shifted, or they will need to be compressed with additional resources applied. 
Figure 3. SAFETY BASIS IMPLEMENTATION

\section{TARGET SCHEDULE}

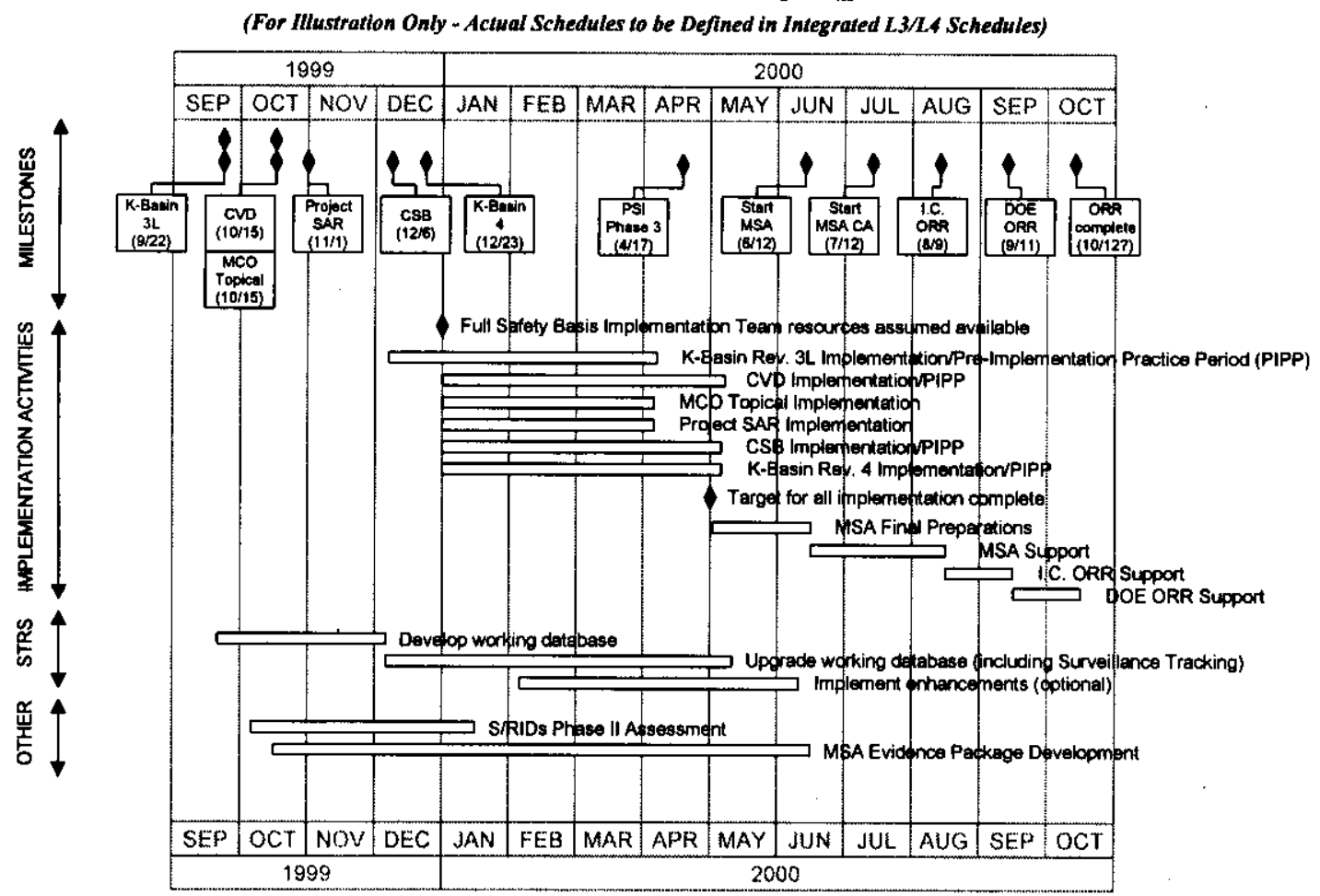

At the top of the Safety Basis. Implementation Schedule, key milestones are shown. Safety Basis implementation activities are preceded by or must support these key milestones. Top-level schedule bars for implementation activities and Management Self Assessment/ Operational Readiness Review (MSA/ORR) support are shown next, followed by activities related to the STRS database and other items. Each top-level schedule bar for a specific Safety Basis Implementation represents the critical path, which is anticipated to encompass commitment identification, implementing document revisions and assessments, and facility quiet time. These top-level bars are 3 months in duration (4 months if a Pre-Implementaton Practice Period is included). A breakdown of the critical path activities for these top-level bars, along with key assumptions, is shown in Figure 4.

K Basins FSAR Revision 3L is shown to start earlier with the limited resources available to support the PSI schedule (current start date December 6, 1999). Some efficiencies may be gained by combining the $\mathrm{K}$ Basins SAR Revision $3 \mathrm{~L}$ and Revision 4 implementation activities; however, because three major facilities will be implementing in parallel, there can be no sharing of resources between the facilities.

April 30, 2000 has been proposed as a target for all implementation to be complete. Due to issues (uncertainty of funding, competing priorities, etc.), it may be necessary to extend implementation activities up to the start of the MSA (current date August 2000). 
Figure 4. TYPICAL SAFETY BASIS IMPLEMENTATION

\section{CRITICAL PATH}

(For Illustration Only - Actual Schedules to be Defined in Integrated L3/L4 Schedules)

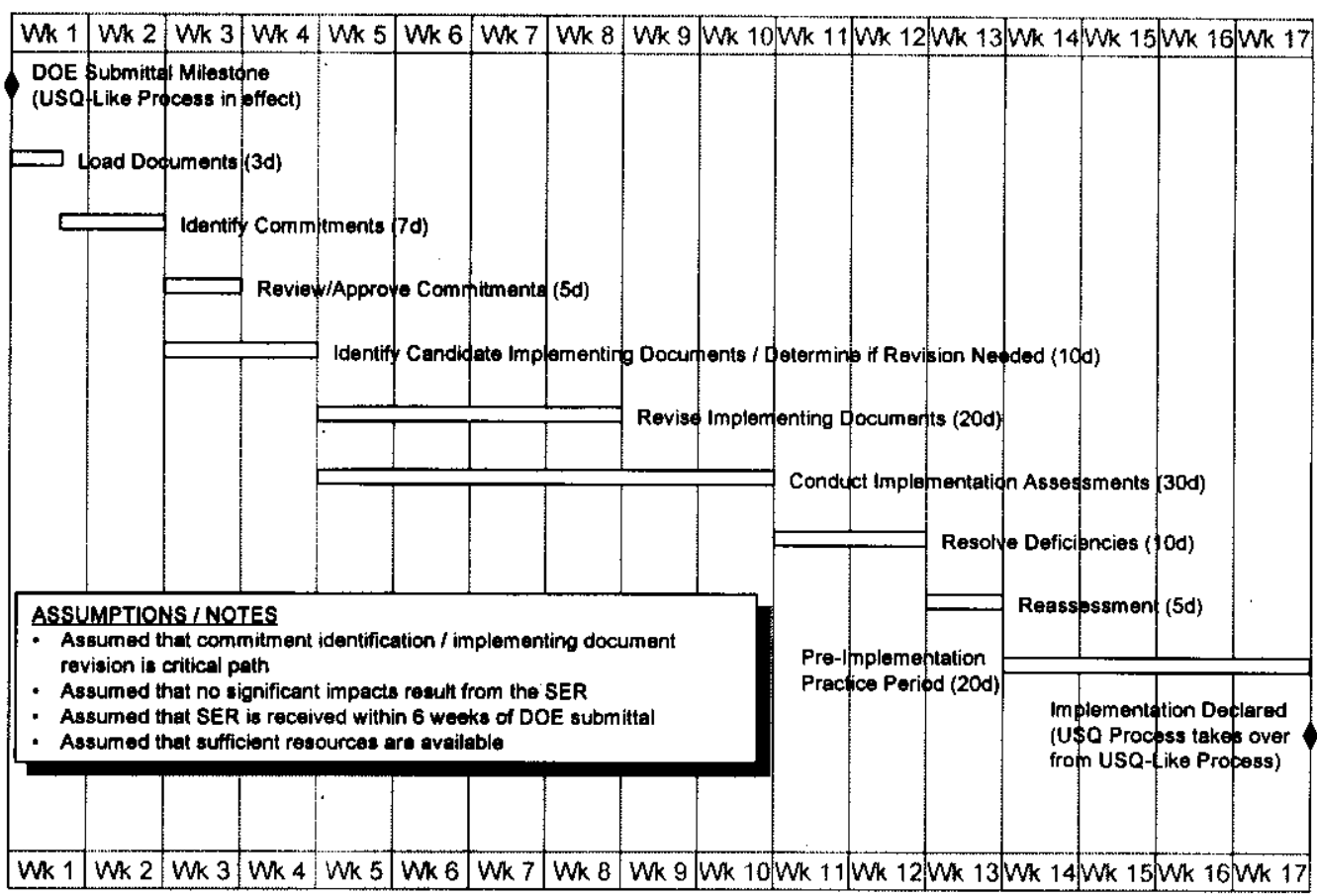

The Safety Basis Implementation effort will be managed as a project, meaning that it will have its own detailed schedule (that can be extracted from the Integrated SNF Project Schedule) and open items list. It is expected that any activity that impacts Safety Basis implementation (even if performed by an outside group) or consumes Safety Basis Implementation Team resources will appear on the detailed Safety Basis Implementation schedule.

\subsection{KEY DELIVERABLES}

Key deliverables under the Safety Basis Implementation project will include the following:

- $\quad$ STRS 2.0

- Functional database (and supporting documentation) required to support readiness to move fuel

- Complete set of data (fully validated and under formal change control)

- Implementation Evaluation Packages for each operational Implementing Document

- USQ-like review packages for all applicable Proposed Activities

- Completed Safety Equipment List

- Functional Classification implementation evaluation documentation 


\subsection{STRS DATABASE}

The SNF Project Technical Requirements (STRS 2.0) database will be the method used by the project to document and track implementation. STRS 2.0 will be developed as part of the Safety Basis Implementation project, using the currently in use working database (contains full text of $\mathrm{K}$ Basins SAR Revision 3L) as the starting point.

Figure 5 shows a simplified diagram of the database tables and relationships. Information flows down from source documents to source document contents to commitments to master commitments to implementation details. Information also flows down from implementing documents to implementation details. The database will also track implementation status; this information will flow in the opposite direction, such that if an implementation detail record is "UNSATISFACTORY," then all related upstream records (back to both the source and implementing document) will be shown to be "UNSATISFACTORY" as well. In this way, the database can serve as a powerful tool to track the progress of implementation.

It should be noted that performance of this process for the $\mathrm{K}$ Basins Safety Basis documents may identify existing inadequacies. If the inadequacies exist in the $\mathrm{AB}$ documentation, they will be handled as potential inadequacies per DOE Order 5480.21. If they exist in other areas, they will be handled by the appropriate document change process. Reportability will be determined on a case-by-case basis.

Figure 5. DATABASE OVERVIEW
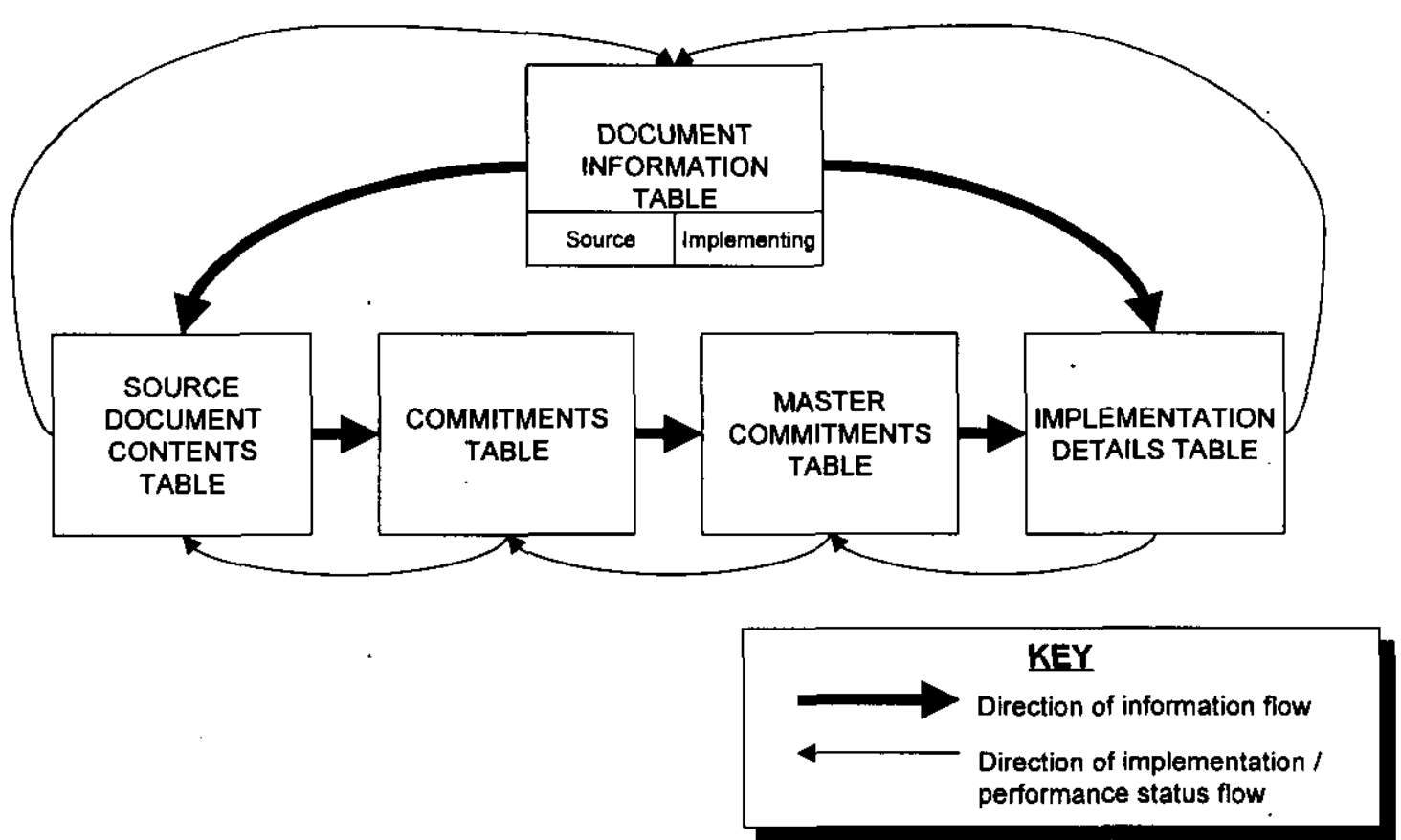
The database is used as follows:

1. Source document details are loaded (initially) or updated (subsequent revisions). Loading may be full text (as is the case with the SAR and TSRs) or selected text.

2. Each new or revised paragraph / table / figure of the source document is evaluated and commitments identified (type and description). One paragraph may have multiple commitments. "Commitment-like" paragraphs may be closed out at this point with the sufficient documented justification.

3. Master Commitments (MC) are developed by grouping topically similar commitments together.

- MCs are at a level of detail such that ideally one and only one operations procedure implements the $\mathrm{MC}$ for a given unit operation (facility, process, component, etc.).

- If the driver for a $\mathrm{MC}$ is in a separate implementing document, another $\mathrm{MC}$ is generated and linked to the first.

- MCs are typically developed using the most detailed requirement as the principal source (e.g., a TSR SR, a PS, etc).

- If an alarm is credited with driving limited conditions for operation (LCO) entry, that generates a MC.

- MCs are totally derived from the related Source Documents. Under no circumstances are MCs to change or interpret the intent of the Source Documents. If clarification is needed, the Source Document itself will be changed (with appropriate reviews and approvals).

4. Candidate implementing documents are entered under the implementation details for each $\mathrm{MC}$, along with facility/unit operation, type (operations, test, etc.), equipment Identification, etc. These are called "candidate" implementing documents because the assessment of implementation has not been performed yet. Therefore, the implementation status is set to "NOT EVALUATED."

5. Candidate implementing documents are evaluated using the linked MCs and a set of review criteria. If the evaluation identifies no deficiencies for a particular $\mathrm{MC}$, that implementation detail will be statused as "SATISFACTORY." Otherwise, deficiencies are logged and the implementation detail is statused as "UNSATISFACTORY."

6. Resolve deficiencies, re-evaluate, and update implementation detail status to "SATISFACTORY."

7. If any record in the database is modified, then associated implementation detail records revert to "NOT EVALUATED."

As mentioned above, a set of review criteria will be used to evaluate a candidate implementing document against each of the Master Commitments it is intended to implement. This review will be performed as part of the MSA reviews concerning procedural implementation of $\mathrm{AB}$ requirements. The list of review criteria topics is provided below:

- Verify that safety equipment (from the safety equipment list [SEL]) is identified.

- Verify that the correct versions of the Safety Basis documents were used in the development process.

- Verify that implementing steps reference the specific source of the requirement (e.g., document and section/requirement number). 
- Verify that limits/actions specified are equal to or more conservative than the most conservative Safety Basis limit/action.

- Verify that actions to take when deviations from the Safety Basis occur are specified.

- Verify that the content includes:

- Spaces for recording all necessary data

- Positive verification that the recorded data indicates compliance with the requirements

- Signoffs by performers and reviewers (at a minimum, the Shift Manager)

- Integration with the Surveillance Tracking System

- Verify that Nuclear Safety approval is documented (and Criticality Safety, if criticality safety implications exist)

In addition, there are a number of topics that must be reviewed once Implementing Documents have been issued and are being used. These reviews are forecast to occur during the PreImplementation Practice Period for each facility. These topics include:

- Verify that the Safety Basis Implementation Matrix is complete (e.g., all cited Implementing Documents confirmed, approved, and issued) for each facility.

- Confirm proper performance of Implementing Documents through field walkdowns, interviews, and spot checks.

- Confirm that systems (e.g., Surveillance Tracking, LCO Tracking) that drive the performance of Implementing Documents are $100 \%$ effective.

- Confirm that there is a procedure in place to drive periodic self-assessments of Safety Basis implementation, and that this procedure is being followed.

\subsection{REFERENCES}

DOE Order 5480.21, "Unreviewed Safety Questions."

DOE Order 5480.22, "Technical Safety Requirements."

DOE Order 5480.23, "Nuclear Safety Analysis Reports."

DOE-STD-3009-94, "Preparation Guide for U.S. Department of Energy Nonreactor Nuclear Facility Safety Analysis Reports."

Project Hanford Management Systems,

TOPICAL AREA: "Engineering Program,"

HNF-PRO-317, "Engineering Release and Approval Requirements," HNF-PRO-439, "Supporting Document Requirements."

TOPICAL AREA: "Quality Assurance," HNF-PRO-233, "Approval of Environmental, Safety, and Quality Documents."

TOPICAL AREA: "Nuclear and System Safety," HNF-PRO-430, "Safety Analysis Program," HNF-PRO-537, "Criticality Safety Control of Fissionable Material,"

HNF-PRO-538, "Criticality Safety Training," HNF-PRO-700, "Safety Analysis and Technical Safety Requirements."

TOPICAL AREA: "Occupational Safety and Health," 
HNF-PRO-081, "Hazardous Energy Control Program."

Spent Nuclear Fuel Project Administrative Procedures,

1-018, "Preparation of K Basins Implementation Plans,"

4-001, "Unreviewed Safety Questions,"

4-002, "Process Standards Administration,"

4-003, "PCA Administration,"

4-004, "Process Standards Nonconformance Administration,"

4-005, "Performance Assurance Process,"

4-013, "Safety Basis Document Implementation Process,"

9-001, "Technical Procedure Administration,"

9-002, "Technical Procedure Development Process,"

9-003, "Technical Procedure Change Process,"

9-004, "Technical Procedure Use and Compliance."

SNF Operations Project Technical Procedures

CP-07-002, "TSR/PS Requirements Verification." 


\section{APPENDIX A}

Facility Safety Basis Implementation Flowchart 


\section{Facility Safety Basis Implementation Flowchart (Sheet 1)}

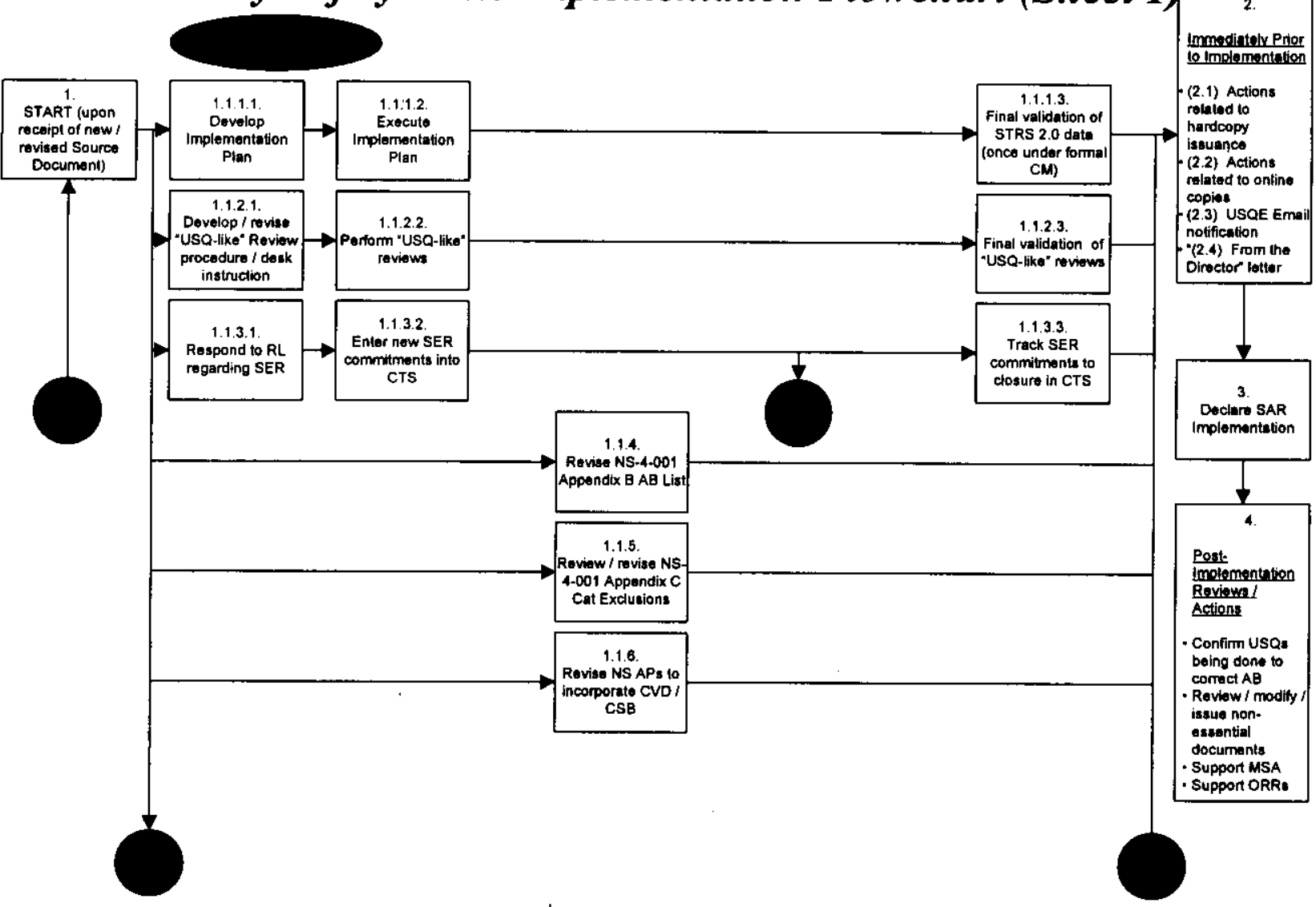




\section{Facility Safety Basis Implementation Flowchart (Sheet 2)}

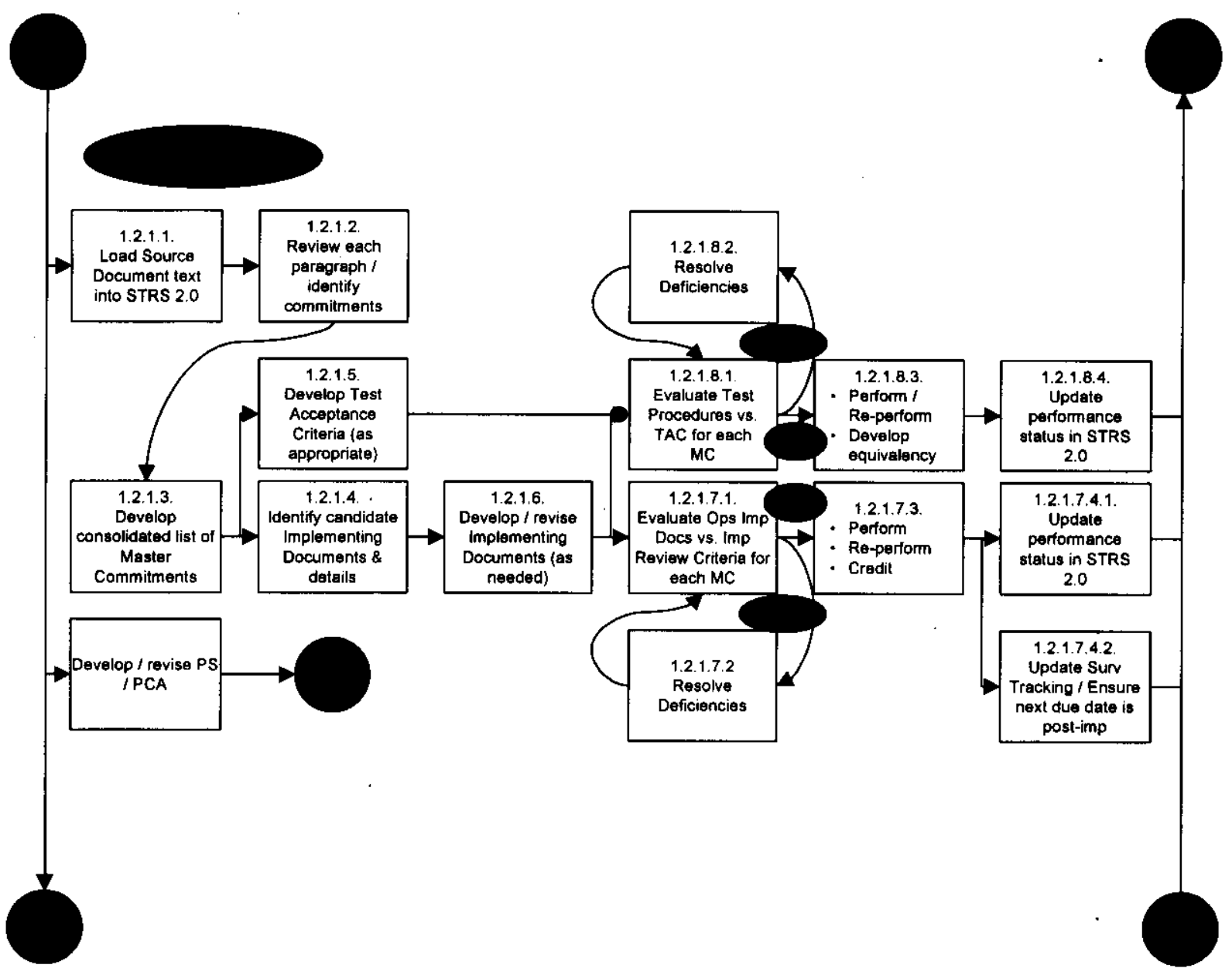




\section{Facility Safety Basis Implementation Flowchart (Sheet 3)}

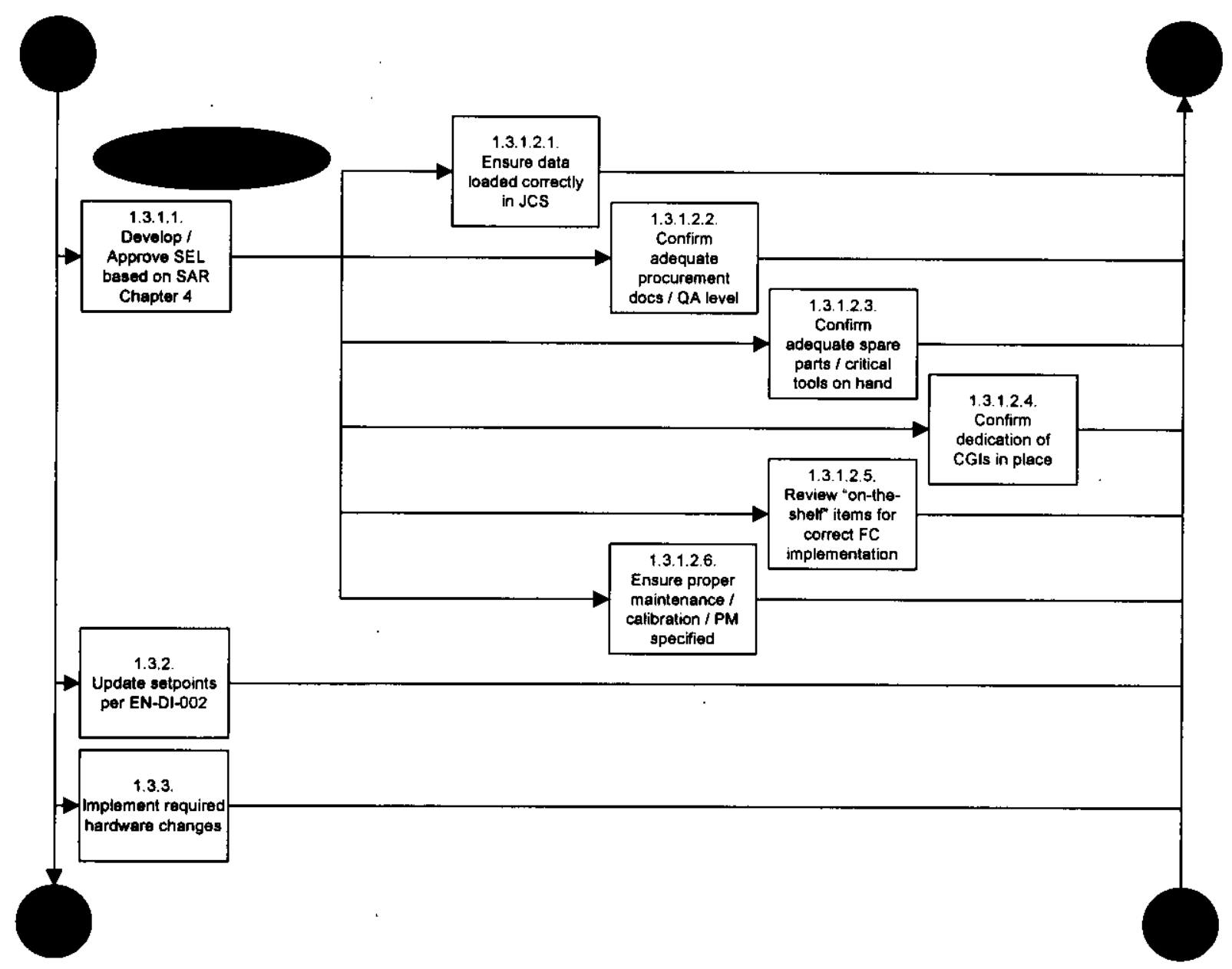




\section{Facility Safety Basis Implementation Flowchart (Sheet 4)}

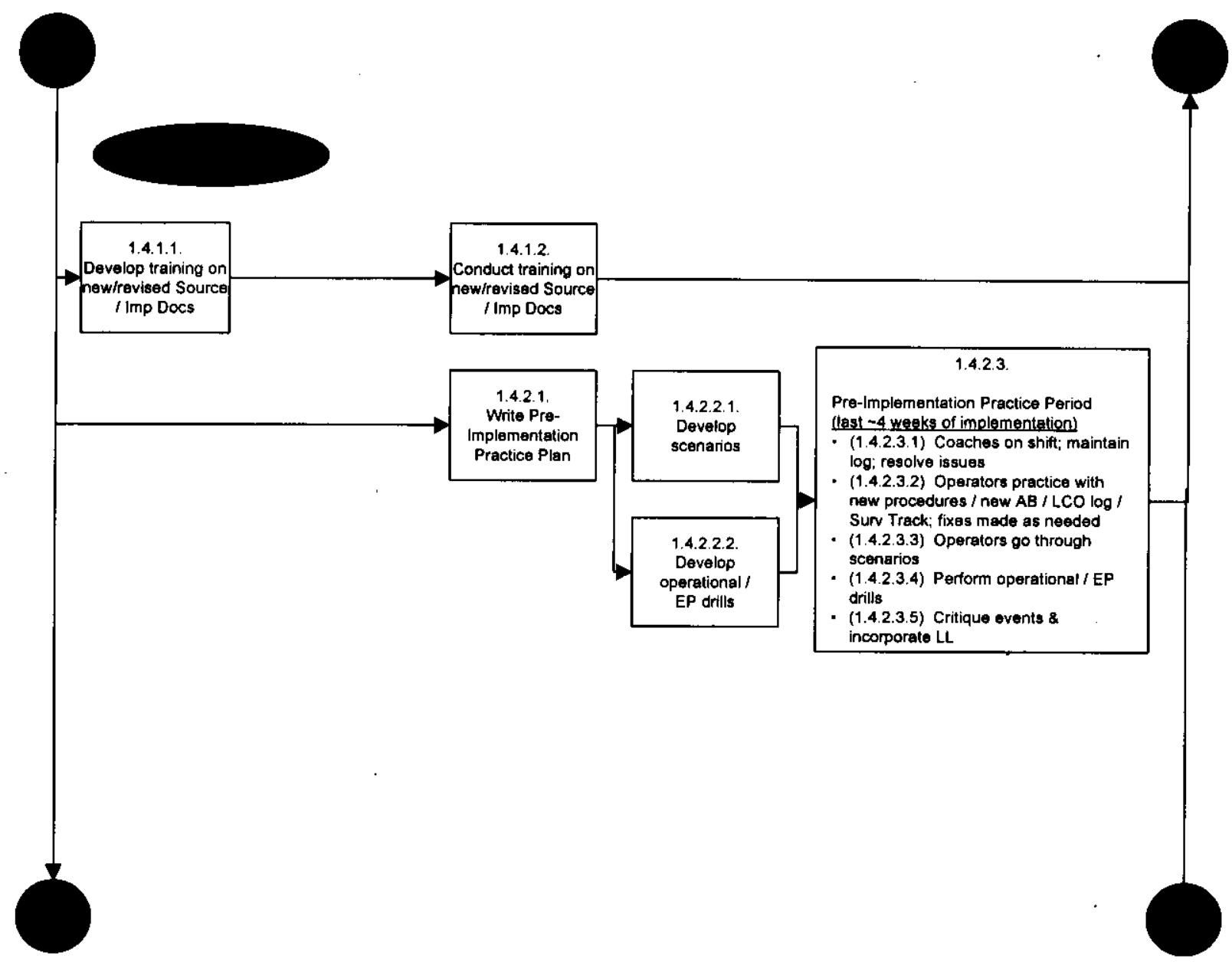




\section{Facility Safety Basis Implementation Flowchart (Sheet 5)}

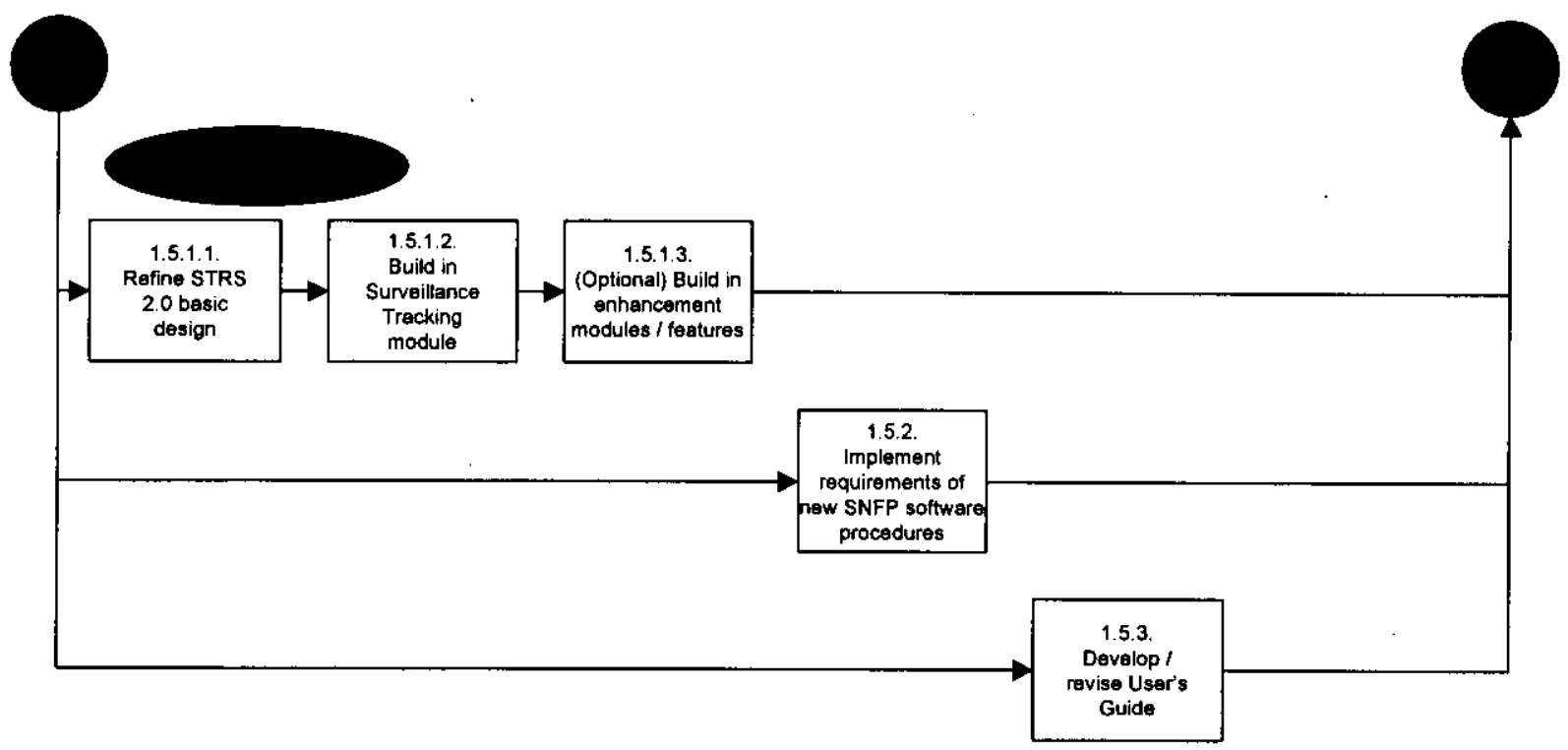




\section{APPENDIX B}

Facility Safety Basis Implementation Flowchart Element Descriptions 
1. START. This flowchart has been developed to describe the activities necessary to bring a facility into full compliance with a set of Source Document requirements, and/or to verify that the facility is already in compliance with those requirements. The goal of this Safety Basis Implementation Program is a $100 \%$ review of Source Document contents, identify what sections contain commitments (and justify why the remaining sections do not contain commitments), ensure that all identified commitments are implemented correctly, completely and consistently in the Implementing Documents and in the hardware. Provide training and coaching to the operating crews, and provide comprehensive documentation of implementation to demonstrate readiness to the MSA and ORR teams. It is expected (in general terms) that this Implementation Program will begin with Source Documents that have been submitted to DOE for review. Changes to these Source Documents resulting from the review comments will be entered into the process at this point (it is expected that such changes will be easily identified via redline/strikeout or other means), they could likely drive a revision to an existing Implementation Plan, versus the development of a new plan. Given that this process will be performed using draft Source Documents and a STRS 2.0 database that is under development, there will be a final validation of the data in STRS 2.0 prior to declaring readiness, and likely prior to declaring implementation.

\subsection{GENERAL}

1.1.1. IMPLEMENTATION PLAN. These activities are high-level tasks that rely on or incorporate tasks from other areas of the implementation program.

\subsubsection{DEVELOP IMPLEMENTATION PLAN. A formal implementation plan will} be developed for each major (set) of Source Document revisions. This implementation plan will follow the path presented in the Facility Safety Basis Implementation Flowchart, and will consider each element depicted in the flowchart. Some elements may not apply, based on the scope of the revisions to the Source Document(s). An integral part of the implementation plan will be a detailed, resource-loaded schedule that lays out all of the activities necessary to achieve implementation. This schedule will be used to establish the implementation date (the effective date of the $\mathrm{AB}$ and Implementing Documents). Development of the implementation plan will begin once the set of new/revised Source Documents is in hand, and will be issued once candidate Implementing Documents have been identified in STRS 2.0.

1.1.1.2.EXECUTE IMPLEMENTATION PLAN. This element involves performance of the applicable elements below. It is shown in the flowchart as a separate element for clarity. Oversight of the Implementation Plan execution will be provided by the PRC. Key to plan execution will be the identification and management of issues related to the implementation effort. These will be tracked in an Implementation Issues database; the resolution of these issues may involve adjusting the implementation strategy or revising a Source Document. 
1.1.1.3.FINAL VALIDATION OF STRS 2.0 DATA. Because implementation will start with draft (non-DOE approved) Source Documents, and because STRS 2.0 will be used while it is still in development and before it is configuration managed, there will be a final validation of the data in STRS 2.0. This validation will ensure that the data aligns fully with $\mathrm{DOE}$-approved source documents, that $100 \%$ of the source document information has been evaluated for commitments, and that Master Commitment statements and implementation details are correct. This activity will be accomplished once STRS 2.0 is under formal configuration control.

1.1 2. USQ-LIKE REVIEWS. Between the time that a Source Document is issued to DOE for approval and the time that implementation of that Source Document is declared, it will be necessary for USQ-like reviews to be performed on all proposed activities at the facility against the submitted Source Document. The purpose of this process is to rigorously ensure that the facility configuration remains consistent with the description in the "pending" $\mathrm{AB}$ until that pending $\mathrm{AB}$ is declared to be implemented and falls under the consideration of the NS-4-001 USQ process.

\subsubsection{DEVELOP / REVISE "USQ-LIKE" REVIEW PROCEDURE / DESK} INSTRUCTION. The existing Nuclear Safety Desktop Instruction (NSDI)-02 will be reviewed (a) to determine if it should remain a NSDI or be upgraded to a procedure; and (b) to determine any changes that may be needed. The conclusion will describe a review process that is applied to the same list of proposed activities that is defined for the USQ process in NS-4-001 (excluding those items listed in the Categorical Exclusions appendix). This will perform a comparison of those proposed activities against the set of "pending" $A B$ documents. The review process must account for not only the documents as originally submitted, but also any comment incorporation that occurs between submittal and approval, as well as additional commitments/conditions imposed by the SER. A mechanism for maintaining the list of "pending" $A B$ documents must be established; in addition, the capability to determine what pending documents have been considered for any one USQ like review must be developed. Immediately prior to implementation, delta reviews can be conducted against pending documents that were not considered (e.g., a change resulting from a review comment; an SER commitment, etc.). This process may also be expanded to consider items not technically part of the official USQ process, such as consideration of PS/PCAs and evaluation of Functional Classification implementation effectiveness. This expansion would serve to consolidate reviews and lead to a more efficient use of resources.

\subsubsection{PERFORM "USQ-LIKE" REVIEWS. It is expected that $100 \%$ of the} proposed activities that meet the criteria requiring a USQ review to be performed (see NS-4-001) would have the USQ like review performed as well. In order to minimize the training required and limit the number of advance copies in circulation, it is anticipated that the USQ like review would 
be performed by only a limited number of reviewers at each facility. Also, in order to prevent the USQ like process from causing delays to critical construction / startup / operational readiness activities, it is acceptable to not require the USQ like review to be completed before the proposed activity is performed. Any discrepancies identified in the USQ like review will be handled on a case-by-case basis.

\subsubsection{FINAL VALIDATION OF "USQ LIKE" REVIEWS. Prior to declaring} implementation, all required USQ like reviews must be verified complete with no outstanding deficiencies.

Note that any deficiencies identified in the USQ like process risk becoming positive USQs once implementation is declared, if they have not been previously resolved. In addition, it must be confirmed that the all of the USQ like reviews considered the final pending $\mathrm{AB}$ content (including comment resolutions and SER commitments or conditions).

\subsubsection{SER ACTIONS.}

1.1.3.1.RESPOND TO RL REGARDING SER. This activity acknowledges the receipt of the SER from RL, and also recognizes any new commitments that may have been imposed by the SER.

1.1.3.2.ENTER NEW SER COMMITMENTS INTO CTS. If the SER introduces any new commitments, these are loaded into the Commitment Tracking System (CTS) for assignment and tracking. Also, if the SER introduces any new commitments, the SER is considered a "New/Revised Source Document" and the commitments enter this process at step 1 (START).

\subsubsection{TRACK SER COMMITMENTS TO CLOSURE IN CTS. Before} implementation, all SER commitments must be verified closed in CTS. In addition, STRS 2.0 will also track this information.

1.1.4. REVISE NS-4-001 APPENDIX B AB LIST. Prior to implementation, the AB list must be revised, so that the USQ process will work effectively following implementation.

1.1.5. REVIEW / REVISE NS-4-001 APPENDIX C CATEGORICAL EXCLUSIONS. Prior to implementation, the categorical exclusion list must be reviewed and revised if necessary, so that only the correct items remain excluded from the USQ process.

1.1.6. REVISE NS APS TO INCORPORATE THE CVD FACILITY / CSB. A number of APs (such as those dealing with implementation, performance assurance, and the USQ process) need to be revised to include the CVD Facility and CSB. These procedures currently only consider K Basins.

\subsection{SOFTWARE}

1.2.1. COMMITMENT IMPLEMENTATION. This set of activities takes the text of Source Documents, identifies commitments, ensures those commitments are correctly / completely / consistently implemented, and confirms that all necessary 
procedures have been performed. The STRS 2.0 database will contain this information and will be used to track progress for each facility (in terms of both correct implementation and performance). For the purposes of this item, Implementing Documents will be divided into two categories, Testing and Operational, each with its own process (because each will be evaluated in a different manner).

\subsubsection{LOAD SOURCE DOCUMENT TEXT INTO STRS 2.0. This element} involves one of two options: full data dump or manual updates. The full data dump is the preferred option for initial loading of a Source Document, as well as when major revisions occur. Full data dump involves taking the Wordperfect (typical) files and importing them into the STRS 2.0 Source Document Contents table. Microsoft Word is used as an intermediate platform, where two macros are run to convert tables to text (one paragraph per table row) and to remove white space. Access then imports the data (one record per paragraph). Following the data import, technical editors will be required to perform two actions, (1); consolidating bulleted lists and their leadin paragraphs into a single record (to clarify the context); (2); embedding tables, figures, or etc., as Microsoft Word objects in the appropriate record (embedding Microsoft Word objects allows the data to be displayed in its original format, which enhances clarity as well). Records that are deemed redundant by this technical editing will then be deleted. If the Source Document revision is minor in nature, the manual update option may be chosen, in which technical editors will update affected records from a redline/strikeout markup of the Source Document. Because the foundation of the Safety Basis Implementation effort is the accuracy of the Source Document contents table, all changes to this table will be independently reviewed by the Safety Basis Implementation Manager or designee before being electronically accepted.

\subsubsection{REVIEW EACH PARAGRAPH / IDENTIFY COMMITMENTS. Once the} data has been loaded into the Source Document contents table, an engineer will review each record to identify commitments. Performance of this process will involve populating the Commitments table of STRS 2.0. If a paragraph contains commitments, they will be added to the Commitments table indicating what sort of commitment it is, (Design Feature, Operational Limit, Action to be Performed, etc.), its functional classification, (SC, SS, or GS-DID), and a verbatim statement from the related Source Document text identifying the commitment. If a paragraph is evaluated to contain no commitments, this status will be entered into the Commitments table, along with appropriate justification. Appropriate justification is made at the discretion of the Safety Basis Implementation Manager, this justification could range from a statement that a paragraph is just for information only, stating the design it describes is not associated with any credited design features in the safety analysis, to referencing a controlled document that justifies why an assumption is conservative enough that it does not need to be procedurally protected. 
1.2.1.3.DEVELOP CONSOLIDATED LIST OF MASTER COMMITMENTS. Once the set of commitments has been identified, this element links those commitments to the Master Commitments table in STRS 2.0, where topically similar commitments are combined and addressed under a single Master Commitment. When properly developed, the Master Commitment list for a facility should represent the "bottom-line" set of $\mathrm{AB} / \mathrm{AB}$-related requirements that a facility is required to implement and maintain. Ideally, Master Commitments should be developed such that each is implemented by one (and only one) operational procedure or other Implementing Document at some level (whether the facility, system, process area/unit operation, or component) - in this way, STRS 2.0 will show implementation completely without the need for additional explanation. However, to maximize flexibility, a discussion field will be provided for cases where explanation is needed (for example, where more than one operational procedure is listed as implementing a given Master Commitment for a specific unit operation/component). Taken together, the set of Master Commitments represents the complete set of $\mathrm{AB}$ / $\mathrm{AB}$-related requirements. It should be noted that commitment identification / Master Commitment development / Implementing Document identification is an iterative process in that lessons learned at one step feed back to other steps and may cause changes to take place at those steps.

\subsubsection{IDENTIFY CANDIDATE IMPLEMENTING DOCUMENTS AND}

DETAILS. Once a Master Commitment has been established, the operational and testing Implementing Documents that should implement the Master Commitment need to be identified. Under this element, the records will be added to the Implementation Details table of the STRS 2.0 database showing the candidate (meaning, "not confirmed to correctly and completely meet the identified Master Commitment") Implementing Document along with the document section, type of commitment, (Operational or Testing), facility/process area/unit operation, component identification number, and any required discussion and/or explanation. Each Implementation Details record will also show the evaluation status (initially, "Not Evaluated"; subsequently "Satisfactory" or "Unsatisfactory") - this information will flow back through the database to allow the progress of implementation for any given Source Document to be statused. Consideration is also being given to having the Implementation Details record show the performance status of the Implementing Document, in order to provide an indication of how much fieldwork remains to be done. As part of this element, an informal review of implementation adequacy will be performed, using the Implementation Review Criteria for operational Implementing Documents, and the Test Acceptance Criteria for testing Implementing Documents. This review will identify what Master Commitments are not currently covered in Implementing Documents, as well as deficiencies within existing Implementing Documents.

\subsubsection{DEVELOP TEST ACCEPTANCE CRITERIA. For those Master}

Commitments which will be implemented by testing category Implementing 
Documents (e.g., data or assumptions in the Master Commitment needs to be proven prior to declaration of readiness), this element addresses developing the list of attributes that must be addressed in the startup test procedures in order to prove the associated sections of the AB. The startup test procedures (or other testing Implementation Documents) will be evaluated under a later element to ensure these attributes are incorporated. Completion of these evaluations for all testing-related Master Commitments ensure that all necessary elements of the $A B$ have been verified by the startup test program.

1.2.1.6.DEVELOP / REVISE IMPLEMENTING DOCUMENTS. Those issues identified as part of the "Identify Candidate Implementing Documents" are resolved as part of this element. This includes developing new Implementing Documents where none currently exist for a Master Commitment, or revising Implementing Documents where deficiencies have been identified in how they implement a Master Commitment. Both operational and testing Implementing Documents are covered by this element. The Implementation Review Criteria for operational Implementing Documents and the Test Acceptance Criteria for testing Implementing Documents will be available to the procedure developers as they perform this element.

\subsubsection{OPERATIONAL IMPLEMENTING DOCUMENT EVALUATION}

\subsection{EVALUATE OPERATIONAL IMPLEMENTING DOCUMENTS} VS. IMPLEMENTATION REVIEW CRITERIA FOR EACH LINKED MASTER COMMITMENT. Under this element, each identified candidate Implementing Document will be assessed to determine if it correctly, completely, and consistently meets all of the Master Commitments that it is linked to in STRS 2.0 Implementation Details table. This assessment will be performed by evaluating the candidate Implementing Document against the set of Implementation Review Criteria for each linked Master Commitment. Criteria that are not met will result in recommendations, which will be tracked to closure. If all criteria are met for a given Master Commitment, then the implementation status will be set to "Satisfactory" in the corresponding Implementation Details table record. Otherwise, the status will be set to "Unsatisfactory." The end result of this element will be the development of an assessment package for each candidate Implementing Document that documents (including redline markups of the Implementing Document) which step/steps implement each criteria of each linked Master Commitment.

1.2.1.7.2. RESOLVE DEFICIENCIES. Recommendations resulting from the evaluation will be submitted via formal change request to the appropriate organization for resolution. Actions to resolve these recommendations will be tracked on the facility's Safety Basis Implementation Plan of the Day. Once all recommendations associated with an Implementing Document have been closed, the Implementing Document is re-evaluated in accordance with the previous element (1.2.1.7.1). Unless the 
Implementing Document undergoes a major revision or complete rewrite per the last element, it is expected that this re-evaluation will only focus on the changes (e.g., a delta review) and will not re-perform the entire review.

1.2.1.7.3. PERFORM / RE-PERFORM / CREDIT [scope considered part of normal operations]. This element addresses the field performance of the Implementing Documents once a "Satisfactory" rating is achieved. This element recognizes three possible scenarios; (there may be others as well): first, initial performance of a procedure; second, re-performance of a procedure, (in the event that the procedure was previously performed, but had to be re-worked as a result of deficiencies identified in the Implementation Review); or third, crediting an already-performed procedure (e.g., the procedure was performed before the evaluation took place, and the evaluation showed that the procedure as originally written achieved a "Satisfactory" rating).

\subsection{STATUSING}

1.2.1.7.4.1:UPDATE PERFORMANCE STATUS IN STRS 2.0. This optional element would be performed if STRS were designated to track performance as well as implementation effectiveness. It could also be combined with the next element if STRS became the Surveillance Tracking system. This is an administrative function that would involve receiving regular reports from operations (or from the Safety Basis Implementation POD which will show these Implementing Document performances) and updating the database. The output of this activity would be a status report that would show the percentage field complete (e.g., performed) by Source Document, set of Master Commitments, etc.

\subsection{UPDATE SURVEILLANCE TRACKING / ENSURE NEXT} DUE DATE IS POST-IMPLEMENTATION. Performance of this element involves loading all completed surveillance procedures into the Surveillance Tracking system, verifying that the next due date calculates correctly, and confirming that the next due date for each surveillance occurs after the implementation date.

\subsubsection{TESTING IMPLEMENTING DOCUMENT EVALUATION}

1.2.1.8.1. EVALUATE TESTING IMPLEMENTING DOCUMENT VS. TEST ACCEPTANCE CRITERIA FOR EACH LINKED MASTER COMMITMENT. Under this element, each identified candidate testing Implementing Document will be assessed to determine if it correctly, completely, and consistently meets all of the Master Commitments that it is linked to in STRS 2.0 Implementation Details table. This assessment will be performed by evaluating the candidate Implementing Document against the set of Test Acceptance Criteria for each linked Master 
Commitment. Criteria that are not met will result in recommendations, which will be tracked to closure. If all criteria are met for a given Master Commitment, then the implementation status will be set to "Satisfactory" in the corresponding Implementation Details table record. Otherwise, the status will be set to "Unsatisfactory." The end result of this element will be the development of an assessment package for each candidate Implementing Document that documents (including redline markups of the Implementing Document) which step/steps implement each criteria of each linked Master Commitment.

1.2.1.8.2. RESOLVE DEFICIENCIES. Recommendations resulting from the evaluation will be submitted via formal change request to the appropriate organization for resolution. Actions to resolve these recommendations will be tracked on the facility's Safety Basis Implementation Plan of the Day. Once all recommendations associated with a testing Implementing Document have been closed, the Implementing Document is re-evaluated in accordance with the previous element (1.2.1.8.1). Unless the Implementing Document undergoes a major revision or complete rewrite per the last element, it is expected that this re-evaluation will only focus on the changes (e.g., a delta review) and will not re-perform the entire review.

\subsection{PERFORM / RE-PERFORM / DEVELOP EQUIVALENCY [scope} considered part of Startup Test program]. This element addresses the field performance of the testing Implementing Documents once a "Satisfactory" rating is achieved. This element recognizes three possible scenarios (there may be others as well): first, initial performance of a test procedure; second, re-performance of a test procedure (in the èvent that the procedure was previously performed, but had to be re-worked as a result of deficiencies identified in the Implementation Review); or third, developing an equivalency document to take credit for data previously obtained which can be used to show that Test Acceptance Criteria have been met (e.g., the procedure was performed before the evaluation took place, and the evaluation showed that the procedure as originally written achieved an "Unsatisfactory" rating, but data could still be used to satisfy certain Test Acceptance Criteria).

\subsection{UPDATE PERFORMANCE STATUS IN STRS 2.0. This optional} element would be performed if STRS were designated to track performance as well as implementation effectiveness. This element is an administrative function that would involve receiving regular reports from the Startup Test group and updating the database. The output of this activity would be a status report that would show the percentage field complete (e.g., performed) by Source Document, set of Master Commitments, etc. 
1.2.2. DEVELOP / REVISE PS / PCA. Revisions to some Source Documents may necessitate changes to the Process Standards and/or Process Change Authorizations (PS / PCAs). In these cases, the applicable PS/PCAs are revised and approved. These changes are then fed into the start of the process, although the resulting impact is expected to be minimal because the PS/PCA changes should align with the other Source Documents.

\subsection{HARDWARE}

1.3.1. EQUIPMENT IMPLEMENTATION. This series of elements is focused on ensuring that all equipment-related items important to the $A B$ are addressed.

1.3.1.1.DEVELOP / APPROVE SEL BASED ON SAR CHAPTER 4. Based on the information contained in SAR Chapter 4, the Safety Equipment List is developed to identify the Safety Class and Safety Significant components and subcomponents.

1.3.1.2.SEL-RELATED REVIEWS. The following series of reviews is intended to ensure that component / subcomponent Functional Classification is correctly implemented in the appropriate functions (e.g., procurement, quality, and maintenance)

\subsection{ENSURE DATA LOADED CORRECTLY IN JCS. Functional} classification information from the SEL is loaded into JCS so that work packages will incorporate the appropriate level of controls.

\subsection{CONFIRM ADEQUATE PROCUREMENT DOCUMENT'S / QA} LEVEL. This activity confirms that procurement documents adequately reflect the requirements associated with a component/subcomponent's functional classification. Included in this activity is verification that the appropriate QA inspection is specified.

\subsection{CONFIRM ADEQUATE SPARE PARTS / CRITICAL TOOLS ON} HAND. Items identified in the Safety Equipment List are reviewed to ensure that an adequate inventory is on hand and is maintained by the system. In addition, this element may also cover ensuring the availability of portable instrumentation, calibration gas, etc.

1.3.1.2.4. CONFIRM DEDICATION OF CGIS IN PLACE. This element involves ensuring that Safety Class and Safety Significant items identified in the Safety Equipment List either are procured as SC/SS items, or have a Commercial Grade Dedication package in place to allow the purchase of GS items instead.

\subsection{REVIEW “ON-THE-SHELF" ITEMS FOR CORRECT FC} IMPLEMENTATION. The intent of this activity is to evaluate items which are already in the system and may be affected by a revised component/subcomponent functional classification. Examples may include work packages as well as Engineering Change Notices / Drawing Change Notices. 


\subsection{ENSURE PROPER MAINTENANCE / CALIBRATION / PM} SPECIFIED. This activity ensures that all safety-related components / subcomponents have the correct maintenance specified in JCS. This activity may involve adding new items into JCS, as well as deleting or modifying items that would be in conflict with the new safety basis requirements.

1.3.2. UPDATE SETPOINTS PER EN-DI-002. This item ensures that the controlled documentation that formally defines setpoints is updated to reflect the latest Source Document information.

1.3.3. IMPLEMENT REQUIRED HARDWARE CHANGES. In the event that the change to the Source Document requires that modifications be made to facility systems, structures, or components, then these modifications must be completed (including testing, turnover, development of operating procedures, etc.) before implementation can be declared.

\subsection{TRAINING}

\subsubsection{CLASSROOM TRAINING}

\subsubsection{DEVELOP TRAINING ON NEW / REVISED SOURCE / IMPLEMENTING} DOCUMENTS. This element may range from a simple briefing on the revisions to a Source Document (more likely at $\mathrm{K}$ Basins) to a comprehensive training class on the $A B$ (what it is, what it contains, how it is used - more likely at the CSB and CVD Facility which are new facilities and will be staffed with people who may not be familiar with this topic). The initial action in this element will be to assess needs and develop a schedule. Topics covered in the training may include: basic information $(\mathrm{AB} / \mathrm{SB}$ orientation, implementation approach), overview of controls and their implementation, and discussion of accidents and associated controls.

\subsubsection{CONDUCT TRAINING ON NEW / REVISED SOURCE /} IMPLEMENTING DOCUMENTS. This element may involve a simple onehour briefing conducted on shift up to a nominal 40-hour classroom session

1.4.2. PRE-IMPLEMENTATION PRACTICE PERIOD. Pre-implementation practice period (PIPP) describes the period of time (proposed to be four weeks) where the operating crew lives to the new Source Document requirements in a practice mode. This means that new Implementing Documents are used (in parallel with current implementing versions if needed), and events are assessed against the new Source Documents (although official event classification is against the AB in effect at the time). Coaches are on shift, and drills are conducted. Implementation is declared at the conclusion of PIPP.

1.4.2.1. WRITE PIPP PLAN. A detailed plan is written to outline the coaching schedule, training scenarios and drills that will be conducted, and the strategy for critiquing events and implementing lessons learned. As part of this activity, a strategy must be developed to allow new Implementing Documents 
to be used in the field, flagging them as "Information Only" if they are inadequate to meet current $\mathrm{AB}$ requirements.

\subsubsection{TRAINING DEVELOPMENT}

1.4.2.2.1. DEVELOP PIPP TRAINING SCENARIOS. These are the tabletop scenarios that coaches and operators will review during PIPP.

1.4.2.2.2. DEVELOP OPERATIONAL / EP DRILLS. These are the drills that will be conducted during PIPP with the goal of demonstrating satisfactory response to situations associated with the new $\mathrm{AB}$.

\subsubsection{PRE-IMPLEMENTATION PRACTICE PERIOD}

1.4.2.3.1. COACHING. Each operating crew will be continuously staffed by two people associated with the Safety Basis Implementation Team. These people will conduct training scenarios, observe normal operations and drills, and keep a formal logbook. Logbook entries will be evaluated for issues and lessons learned; these items will be added to the Safety Basis Implementation Issues List for tracking, assignment, prioritization (immediate, pre-implementation, or post-implementation), and closure. Coaches will also be responsible for feeding information and lessons learned back to their respective operating crews.

1.4.2.3.2. OPERATING CREW PRACTICE. The operating crews will use PIPP to familiarize themselves with the new set of Source and Implementing Documents. These documents will be available in a format that clearly identifies them as "Information Only" unless a particular Implementing Document is being used to implement current $\mathrm{AB}$ requirements. Information Only Implementing Documents will be performed alongside the currently approved set of Implementing Documents.

\subsection{TRAINING SCENARIOS. Coaches will take each operating crew} through a series of tabletop scenarios designed to familiarize the crews with the purpose, use, and applicability of the AB. Some of the focus will be on controls that are predicted to be the most difficult to understand / implement / track. It is expected that the performance of these scenarios will raise questions and issues which will be captured in the coaches' log for processing.

1.4.2.3.4. OPERATIONAL / EP DRILLS. Each crew will perform a set of drills (details to be provided by the PIPP Plan) to formally demonstrate proficiency with the new $A B$, both in response to identification of conditions outside of an LCO/LCS/SL and in response to emergency events.

\subsection{CRITIQUE EVENTS / INCORPORATE LESSONS LEARNED. It is} expected that during the PIPP, "events" will occur in relation to the new controls / Implementing Documents being practiced. Following declaration of implementation, these would be officially classified and 
assessed. Prior to implementation, these events will be unofficially classified, and will undergo the same level of evaluation / analysis as an officially declared occurrence. The goal of this process is to identify and implement lessons learned, so that the number of actual events following implementation will be reduced.

\subsection{STRS}

\subsubsection{STRS 2.0 DESIGN}

1.5.1.1.REFINE STRS 2.0 BASIC DESIGN. This element involves building the needed functionality into the STRS 2.0 working version. Included are building in the design of ACM 2.0, as well as incorporating features as requested by key end-users. Under this element, the database exists entirely in Microsoft Access.

1.5.1.2.BUILD IN SURVEILLANCE TRACKING MODULE. This element integrates a Surveillance Tracking module into STRS 2.0 that would take the place of the performance assurance datasheet.

\subsubsection{3.(OPTIONAL) BUILD IN ENHANCEMENT MODULES / FEATURES}

\subsection{BUILD IN LCO TRACKING MODULE. This optional element} would enable STRS 2.0 to track the completion status and due date/time of $L C O$ required actions.

1.5.1.3.2. LOAD HYPERLINKS. This optional element would load path information into STRS 2.0 such that an end-user could click on a link and open the referenced Source or Implementing Document. It should be noted that earlier STRS documents envisioned that HTML files of each document would be created and maintained; however, this represents additional work required in the area of electronic document maintenance (the SNF Project standard is MS Word). If hyperlinks are desired, they can be made using Word files; however, there are other issues to consider as well, such as the fact that the filename usually contains the revision and thus the link would have to be updated at every change, and the need to establish a procedure to control document modifications, such that bookmarks within a file (to which the hyperlink points) are not adversely affected.

1.5.1.3.3. LINK TO S/RIDs DATABASE. This element would allow a STRS user to view S/RIDs compliance information. This element is considered optional because there is already a database that provides this capability. Consolidating the information in STRS would be an enhancement, and could be pursued following implementation if desired.

\subsection{BUILD IN ENVIRONMENTAL COMPLIANCE INFORMATION.} This activity would incorporate the environmental requirements implementation tables / matrices (see EP-5-018, SNF Project . Environmental Basis Performance Assurance Process, Appendix A) into 
STRS. Because both STRS and the environmental matrices contain links to Process Standards, consolidation of the information has merit. However, in terms of readiness to move fuel, consolidation is not required, and thus this is an optional activity.

1.5.1.3.5. MIGRATE DATA TO SQL TABLES ON SERVER. Once the database design is finalized on the Access platform, this optional element would transfer the data to SQL tables for enhanced performance and security.

1.5.1.3.6. DEVELOP WEB-BASED FRONT END. If desired, the final step would be to establish a Web front-end. Again, this is optional, and would be done only if deemed beneficial.

\subsubsection{IMPLEMENT REQUIREMENTS OF NEW SNF Project SOFTWARE}

PROCEDURES. Administrative Procedure CM-6-013, Software Configuration Management, was recently issued. This procedure, together with other SNF Project procedures on Electronic Data Management, Software Verification and Validation, and Software Development (these other procedures are expected to be issued as Revision 0 in the near future) applies to STRS 2.0 and will have to be implemented. The exact scope can only be determined after the balance of the procedures have been issued, but in general terms the scope is expected to involve formal documentation of the database design, testing, establishment of a configuration management program to ensure data integrity, etc.

1.5.3. DEVELOP / REVISE USER'S GUIDE. The user's guide will cover topics of interest to end-users and system administrators.

2. IMMEDIATELY PRIOR TO IMPLEMENTATION. The following set of activities occurs (typically) the day of implementation.

2.1. ACTIONS RELATED TO HARDCOPY ISSUANCE. Controlled versions of the AB documents are manually updated and independently confirmed to be correctly updated. New Implementing Documents are also issued to the field. In addition, the documents are released through the Document Control Stations.

2.2. ACTIONS RELATED TO ONLINE COPIES. Files containing the new AB documents, Process Standards/PCAs, and Implementing Documents are uploaded to the server.

2.3. USQE E-MAIL NOTIFICATION. An e-mail is issued to all USQEs informing them of the revision to the $\mathrm{AB}$ and the need to use the updated documents in the performance of USQ screenings/evaluations.

2.4. "FROM THE DIRECTOR" LETTER. A letter announcing the new $A B$ and other associated documents is issued to all Project personnel from the SNF Project Director.

3. DECLARE SAFETY BASIS IMPLEMENTATION. Once all pre-requisite actions have been confirmed complete, the PRC declares the new $\mathrm{AB}$ documents to be implemented.

4. POST-IMPLEMENTATION REVIEWS. 
4.1. CONFIRM USQS BEING DONE TO CORRECT AB. In the month (typical) following implementation, USQ screenings and evaluations are sampled to ensure that the correct set of $\mathrm{AB}$ documents is being considered.

4.2. REVIEW / MODIFY / ISSUE NON-ESSENTIAL DOCUMENTS. (Giving a document "non-essential" status is subject to PRC concurrence that the document is in fact, nonessential to implementation). Documents that were deferred past implementation are completed. In general, it is assumed that these documents must be updated prior to declaring readiness to move fuel.

4.3. SUPPORT MSA. This activity provides support related to the Safety Basis Implementation effort for the MSA. This encompasses developing evidence packages, resolving open action items, defending conclusions to the assessment team, and closing on any follow-up items.

4.4. SUPPORT ORRs. This activity provides support related to the Safety Basis Implementation effort for the independent contractor ORR and the DOE ORR. This involves providing assessment material to the ORR team, defending conclusions, and closing on any follow-up items. 